\title{
REVIEW
}

\section{Notch3 Signaling and Aggregation as Targets for the Treatment of CADASIL and Other NOTCH3-Associated Small-Vessel Diseases}

\author{
Dorothee Schoemaker ${ }^{* \dagger}$ and Joseph F. Arboleda-Velasquez
}

From the Department of Psychiatry, * Massachusetts General Hospital, Harvard Medical School, Boston; and the Schepens Eye Research Institute of the Mass Eye and Ear and Department of Ophthalmology of Harvard Medical School, ${ }^{\dagger}$ Boston, Massachusetts

Accepted for publication

March 19, 2021.

Address correspondence to Joseph F. Arboleda-Velasquez, M.D., Ph.D., Schepens Eye Research Institute of Mass Eye and Ear, 20 Staniford St., Boston, MA 02114; or Dorothee Schoemaker, Ph.D., Department of Psychiatry, Massachusetts General Hospital, 50 Fruit St., Boston, MA 02114. Email: dschoemakermarcotte@ mgh.harvard.edu or joseph_ arboleda@meei.harvard.edu.

\begin{abstract}
Mutations in the NOTCH3 gene can lead to small-vessel disease in humans, including the well-characterized cerebral autosomal dominant arteriopathy with subcortical infarcts and leukoencephalopathy (CADASIL), a condition caused by $\mathrm{NOTCH} 3$ mutations altering the number of cysteine residues in the extracellular domain of Notch3. Growing evidence indicates that other types of mutations in NOTCH3, including cysteine-sparing missense mutations or frameshift and premature stop codons, can lead to small-vessel disease phenotypes of variable severity or penetrance. There are currently no disease-modifying therapies for small-vessel disease, including those associated with NOTCH3 mutations. A deeper understanding of underlying molecular mechanisms and clearly defined targets are needed to promote the development of therapies. This review discusses two key pathophysiological mechanisms believed to contribute to the emergence and progression of small-vessel disease associated with NOTCH3 mutations: abnormal Notch3 aggregation and aberrant Notch 3 signaling. This review offers a summary of the literature supporting and challenging the relevance of these mechanisms, together with an overview of available preclinical experiments derived from these mechanisms. It highlights knowledge gaps and future research directions. In view of recent evidence demonstrating the relatively high frequency of NOTCH3 mutations in the population, and their potential role in promoting small-vessel disease, progress in the development of therapies for NOTCH3-associated small-vessel disease is urgently needed. (Am J Pathol 2021, 191: 1856-1870; https://doi.org/10.1016/j.ajpath.2021.03.015)
\end{abstract}

Cerebral autosomal dominant arteriopathy with subcortical infarcts and leukoencephalopathy (CADASIL) is a hereditary disease caused by mutations on the NOTCH3 gene and leading to early onset of progressive small-vessel disease. $^{1,2}$

The core clinical manifestations of CADASIL consist of the early and recurrent onset of cerebral ischemic events (transient ischemic attacks and ischemic strokes), and progressive vascular cognitive impairment. ${ }^{1}$ CADASIL has been associated with other neurologic symptoms occurring at varying frequency within affected patients, including migraines with aura, mood disorders, gait disturbances, intracerebral hemorrhages, movement abnormalities (eg, parkinsonism), and seizures. ${ }^{1}$ For reasons still poorly understood, there is an important phenotypic variability in the type, severity, and progression of symptoms in patients with CADASIL, even within members of a same family. ${ }^{1}$ Despite this important clinical variability, CADASIL is a progressive disease often leading to dementia, disability,

Supported by NIH grants cofunded by the National Institute of Neurological Disorders and Stroke and the National Institute on Aging RF1NS110048-01, UH3NS100121, and 1U01NS119560 (J.F.A.-V.); and the CureCADASIL organization research funding (J.F.A.-V. and D.S.).

Disclosures: J.F.A.-V. is listed as an inventor in patents for the use of Notch 3 agonists in the treatment of small-vessel diseases and for blood biomarkers in CADASIL. D.S. postdoctoral fellowship was funded by the American Heart Association 20POST35110047 and the Fonds de Recherche du Québec-Santé 254389.

This article is part of a review series on small blood vessel disease in the brain, addressing current knowledge, new mechanisms, biomarkers, and therapeutic approaches. 
and earlier mortality. ${ }^{3}$ There is currently no approved disease-modifying therapy for CADASIL, and treatment is usually centered around symptom management. ${ }^{4}$ There is thus an urgent need for therapies to alter the course of the disease before the onset of debilitating and potentially fatal symptoms. Yet, the limited insight into disease pathophysiological mechanisms and the current lack of clearly defined therapeutic targets constitute important obstacles to therapeutic developments.

\section{NOTCH3 Mutations in CADASIL: Characteristics and Epidemiology}

CADASIL is caused by mutations on the NOTCH3 gene located on chromosome 19p13, a gene involved in the differentiation and maturation of vascular smooth muscle cells, vascular development during embryogenesis, and vascular integrity. ${ }^{5-9}$ The NOTCH3 gene encodes a 2321-amino acid long cell surface receptor, ${ }^{8}$ a protein composed of three regions: an extracellular domain (ECD) regrouping 34 epidermal growth factor-like repeats (EGFRs) and three cysteine-rich Lin-12/Notch (LNR) repeats that interact with membrane-bound ligands of the Delta or Jagged/Serrate protein families (Jagged 1 and 2 and Delta-like 1, 3, and 4 in mammals), a single transmembrane domain, and an intracellular domain containing six ankyrin repeats (ANK) together with a recombination signal binding protein for immunoglobulin Kappa J region (RBPJ) association molecule (RAM) and a proline, glutamine, serine, and threonine rich (PEST) region ${ }^{9}$ (Figure 1). ${ }^{10-12}$ The Notch3 receptor is expressed in mural cells (namely, vascular smooth muscle cells and pericytes) of small arteries throughout the body, with an apparent predilection for brain vessels. ${ }^{13-16}$ Activation of the Notch3 receptor results in the up-regulation of RBPJ-dependent Notch target gene expression (HES1, HEYL, HRT1, HRT2, and others), possibly promoting growth and modulating apoptosis of mural cells. ${ }^{17}$
Over 200 unique CADASIL-causing mutations have been identified in NOTCH3. ${ }^{10,18}$ The vast majority of these mutations occur within exons 2 to 24 of $\mathrm{NOTCH} 3$, that encodes the extracellular domain of the Notch3 receptor (Notch3ECD). 18 Each EGFR of the Notch $3^{\text {ECD }}$ normally contains a highly conserved number and position of six cysteine residues, forming three disulfide bonds playing a role in the stabilization of the Notch $3^{\mathrm{ECD}} \cdot{ }^{19}$ CADASIL-causing mutations almost invariably result in the addition or deletion of a cysteine residue within one of the EGFRs, leading to an odd number of cysteine residues. ${ }^{20}$ The unpaired number of cysteine residues is believed to alter the formation of disulfide bridges, which, in turn, affects the stability of Notch $3^{\mathrm{ECD}}$ and potentially promotes misfolding, aggregation, and aberrant function of the receptor. ${ }^{19-22}$ CADASIL mutations have been described across all 34 EGFRs of the Notch $3^{\mathrm{ECD}}$, with an increased clustering of pathogenic mutations around the first to sixth EGFR. ${ }^{20}$ In addition to mutations affecting cysteine residues, there are also several reports of cysteine-sparing missense mutations leading to a small-vessel disease phenotype. ${ }^{23} \mathrm{~A}$ recent review of the literature suggests that some patients harboring cysteinesparing NOTCH3 missense mutations, particularly the p.R61W, p.R75P, p.D80G, and p.R213K mutations, present with a clinical syndrome consistent with CADASIL. ${ }^{23}$ Yet, there is ongoing debate on whether these mutations are fully pathogenic and lead to the expression of the full spectrum of CADASIL phenotypic characteristics. ${ }^{18}$ Although CADASIL-causing mutations are for the vast majority heterozygous, a few cases with homozygous NOTCH3 mutations have been reported. Patients with homozygous NOTCH3 mutations appear to present a clinical phenotype falling within the classic clinical spectrum of CADASIL, whereas some reports highlight an increased disease severity in homozygous carriers. ${ }^{24-26}$ Findings from studies focusing on the clinical presentation of individuals carrying homozygous NOTCH3 mutations must, however, be interpreted with caution as it remains difficult to disentangle the effect of clinical variability from homozygosity in these rare cases.

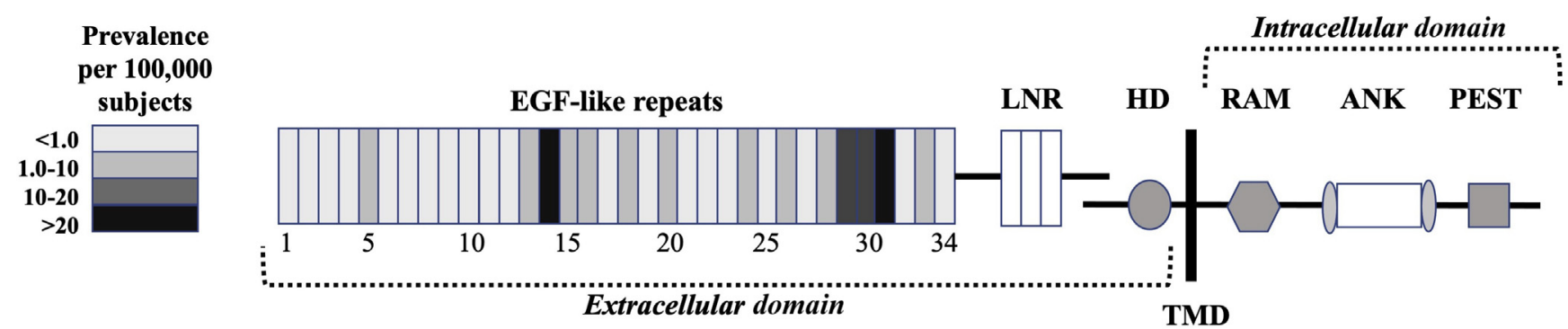

Figure 1 Schematic illustration of the Notch3 receptor. Each epidermal growth factor (EGF)-like repeat (EGFR) is color coded on the basis of pooled prevalence estimates of cysteine-altering NOTCH3 mutations affecting this EGFR derived from recently published studies (Rutten et al, ${ }^{10}$; Rutten et al, ${ }^{11}$; and Hack et $\mathrm{al}^{12}{ }^{12}$ ) examining three large exome databases (UK Biobank, Exome Aggregation Consortium; ExAC, and Geisinger DiscovEHR). ANK, ankyrin repeats; HD, heterodimerization domain; LNR, Lin-12/Notch Repeat; PEST, proline (P), glutamine (E), serine (S), and threonine (T) rich region; RAM, recombination signal binding protein for immunoglobulin Kappa J region (RBPJ) association molecule; TMD, transmembrane domain. 
CADASIL is a rare disease, with an estimated prevalence ranging from 1.98 to 4.6 per 100,000 in the general population. ${ }^{27-29}$ However, recent work suggests that canonical cysteine-altering NOTCH3 mutations are far more prevalent than previously reported. ${ }^{27-29}$ For instance, relying on publicly accessible exome databases, recent studies estimated that the prevalence of cysteine-altering NOTCH 3 mutations ranges from 2.2 to 3.4 per 1000 cases, a prevalence nearly 100 -fold higher than previously available estimates for CADASIL. ${ }^{10-12}$ The apparent mismatch between estimates of disease and mutation prevalence is not well understood, but likely reflects fluctuating degrees of penetrance or severity associated with these mutations. This interpretation is consistent with evidence indicating that not all NOTCH3 mutation carriers become symptomatic, a statement that applies to both cysteine-altering, cysteine-sparing mutations and bona fide $\mathrm{NOTCH} 3$ loss-of-function mutations, as discussed later in the review. ${ }^{11,23,30}$

\section{Pathophysiological Characteristics of CADASIL}

On microscopic examination, CADASIL shares many key pathophysiological features with sporadic forms of smallvessel disease, including degeneration of mural cells, small lacunar infarcts, atrophic myocytes and vascular endothelial cells, narrowing of the lumen, thickening of vessel wall, fibrosis, and subcortical white matter rarefication ${ }^{1}$ (Figure 2). Patients and mouse models with CADASIL mutations show early alterations in cerebrovascular blood flow and hemodynamics, which have been proposed as potentially useful biomarkers for clinical trials. ${ }^{31,32}$

Another key pathologic hallmark of CADASIL is the intravascular accumulation of granular osmiophilic material (GOM) deposits, consisting of microscopic electron-dense particles found in the basement membrane of arteries, arterioles, and capillaries of patients with CADASIL. ${ }^{33,34}$ Although its exact composition remains largely unknown, studies have repeatedly demonstrated that Notch $3^{\mathrm{ECD}}$ is a major component of GOM. ${ }^{14,22,35-37}$ Although GOM deposits are found in other organs of patients with CADASIL, such as the skin, they are more abundant in the brain. ${ }^{14,37}$ The accumulation of GOM is considered a pathognomonic feature of CADASIL and is viewed as a critical pathogenic mechanism contributing to the degeneration of mural cells and increased stroke susceptibility in affected patients. ${ }^{38}$ Yet, mechanisms linking GOM aggregation to cerebrovascular abnormalities and clinical symptoms have not been fully elucidated.

Another hypothesis holds that NOTCH3 mutations lead to aberrant signaling or activity of the Notch 3 receptor. This hypothesis is supported by compelling evidence that Notch3 loss of function in humans and mouse models is sufficient to cause mural cell degeneration and small-vessel disease, even in the absence of GOM aggregation. ${ }^{16,22,39-43}$
Similar to the situation in other neurodegenerative diseases, such as familial autosomal dominant Alzheimer disease, the discussion surrounding pathophysiological mechanisms in CADASIL has been the subject of much debate. At least two mechanisms have been proposed to contribute to vascular degeneration in individuals and animal models with NOTCH3 mutations and small-vessel disease: NOTCH3 mutations result in Notch3 receptor misfolding and aggregation, triggering GOM formation and affecting vessel structural and functional integrity; and NOTCH3 mutations alter function of the Notch3 receptor, leading to mural cell dysfunction and degeneration. The field has reached the point where enough evidence supports the plausibility of both the Notch3 accumulation cascade and the Notch3 signaling abnormality hypotheses. This review focuses on summarizing the literature on the role of Notch3 aggregation and signaling in CADASIL, as well as exploring potential clinical implications derived from these findings.

\section{The Role of Protein Accumulation in CADASIL}

\section{Proposed Mechanisms and Supporting Evidence}

In CADASIL, Notch $3^{\mathrm{ECD}}$ accumulates as microscopic extracellular aggregates at the plasma membrane of vascular smooth muscle cells and pericytes and is a core component of GOM. Deposits of GOM are found in virtually all mouse models and patients carrying cysteine-altering NOTCH3 mutations and appear at an early stage in the disease, suggesting a central role in the disease process. ${ }^{35,38,44,45}$

Evidence suggests that the accumulation of Notch $3^{\mathrm{ECD}}$ in CADASIL is linked to alterations in the formation of disulfide bridges caused by the uneven number of cysteine residues resulting from the mutation, leading to instability of the receptor's extracellular domain, misfolding, and enhanced multimerization properties. ${ }^{19,21}$ In support of this hypothesis, Notch $3^{\mathrm{ECD}}$ was found to accumulate in disulfide cross-linked insoluble aggregates and show increased binding affinity to other proteins. ${ }^{21,46-48}$ Perhaps serving as a seeding agent, Notch $3^{\mathrm{ECD}}$ was found to aggregate and colocalize with several extracellular matrix proteins, including tissue inhibitor of metalloproteinases-3 (TIMP3), vitronectin, clusterin, endostatin, and latent transforming growth factor- $\beta$ binding protein 1 , in the vasculature of mice harboring CADASIL mutations. ${ }^{22,37,47,49,50}$ It has been suggested that this aggregation alters normal cellular function and offers new binding surfaces that further facilitate toxic aggregation of proteins, eventually generating a snowball effect. ${ }^{45,47,51,52}$ In agreement with this notion, the number, size, and morphology of GOM deposits evolve through the course of the disease. ${ }^{53}$ In vitro studies have demonstrated reduced clearance and decreased solubility of mutant Notch3 protein complexes compared with wild type. ${ }^{46}$ Impaired perivascular drainage $\mathrm{e}^{54,55}$ and dysfunctions in autophagy processes ${ }^{56}$ are other mechanisms possibly 
A

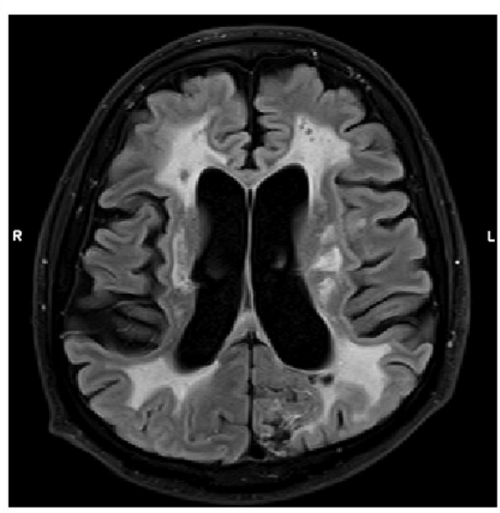

B

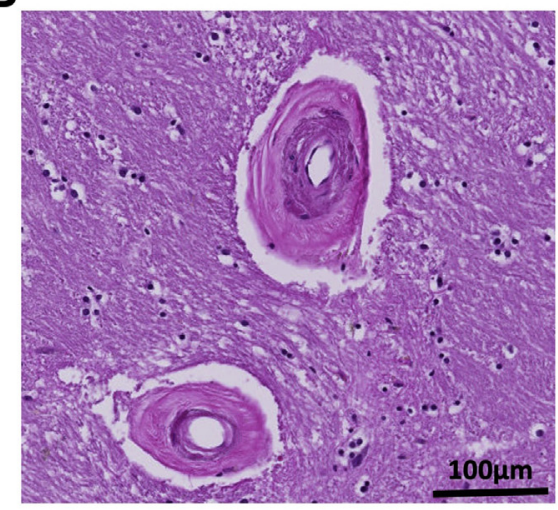

C

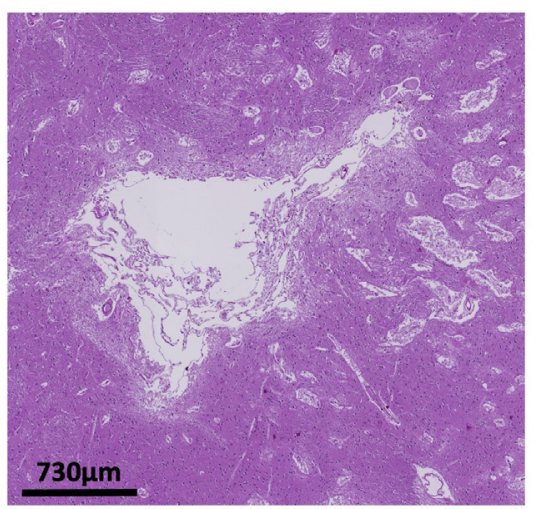

Figure 2 Illustration of neuropathologic features in cerebral autosomal dominant arteriopathy with subcortical infarcts and leukoencephalopathy (CADASIL). A: Sagittal 3-T magnetic resonance imaging (MRI) fluid-attenuated inversion recovery image in a 52-year-old patient with CADASIL, showing widespread white matter hyperintensity, lacunes, and atrophy. B: Representative hematoxylin and eosin (H\&E) staining of the basal ganglia of a deceased patient with CADASIL, showing vessel wall thickening and dilated perivascular spaces. C: H\&E staining of the basal ganglia of a deceased patient with CADASIL, showing ischemic lesions and white matter rarefication. MRI image kindly provided by Dr. Yakeel Quiroz (Massachusetts General Hospital, Boston, MA), and postmortem histopathologic images kindly provided by Dr. Diego Sepulveda-Falla (Institut für Neuropathologie Universitätsklinikum Hamburg-Eppendorf, Hamburg, Germany). Scale bars: $100 \mu \mathrm{m}$ (B); $730 \mu \mathrm{m}$ (C).

contributing to the extracellular accumulation of insoluble proteins in CADASIL. Abnormal protein aggregation has been described as a key pathophysiological mechanism in other neurodegenerative diseases, including Alzheimer disease and cerebral amyloid angiopathy. ${ }^{57}$ It has therefore been suggested that CADASIL falls within the spectrum of protein elimination failure angiopathies. ${ }^{55}$

Some evidence supports the pathogenic role of GOM aggregation in CADASIL. First, the accumulation of Notch $3^{\mathrm{ECD}}$ is one of the earliest detectable pathologic features in mouse models and humans with CADASIL and appears before the formation of GOM deposits. ${ }^{13,58,59}$ This suggests that Notch $3^{\mathrm{ECD}}$ accumulation is an early event in CADASIL that possibly initiates a pathogenic cascade of protein aggregation, leading to the formation of GOM. Mouse model studies and in vitro studies have confirmed that CADASIL mutations promote the abnormal accumulation of $\mathrm{Notch}^{\mathrm{ECD}}$ and GOM within the vasculature. ${ }^{21,47,48}$ Furthermore, the expression level of mutant Notch 3 in mouse models correlates with the age of onset and severity of Notch $3^{\mathrm{ECD}}$ accumulation around vessels. ${ }^{58}$ Increased levels of TIMP3, a protein found to aggregate with Notch $3^{\mathrm{ECD}}$ in CADASIL, lead to an up-regulation of voltage-gated potassium channels and a disruption in myogenic tone and cerebrovascular reactivity through inhibition of the disintegrin and metalloproteinase domaincontaining protein 17 (ADAM17). ${ }^{52,60}$ A transgenic mouse model overexpressing human TIMP3 displays similar alterations in cerebrovascular blood flow and myogenic response as those observed in a CADASIL mouse model, suggesting shared mechanisms. ${ }^{52,61}$ These results support a mechanistic link between abnormal protein aggregation and cerebrovascular dysfunctions in CADASIL. Yet, direct in vitro or in vivo evidence confirming the toxicity of GOM-
Notch $3^{\text {ECD }}$ or associations with clinical features of CADASIL is lacking. Filling this knowledge gap requires the development of methods for GOM-Notch $3^{\mathrm{ECD}}$ purification and the establishment of relevant experimental paradigms to evaluate mural cell dysfunction and degeneration in the presence of GOMs.

\section{Therapeutic Implications and Preliminary Evidence}

If the progression of CADASIL is fully or partly caused by abnormal protein aggregation, then the use of agents preventing or clearing this aggregation may improve disease manifestations or progression.

A recent proof-of-concept study by the research team of Dr. Anne Joutel, pioneer and leader in the field of CADASIL, investigated the therapeutic value of immunotherapy targeting Notch $3{ }^{\mathrm{ECD}}{ }^{62}$ For a period of 20 weeks, CADASIL mutant mice $\left(\right.$ TgNotch $3^{\mathrm{R} 169 \mathrm{C}}$ ) were peripherally administered monoclonal antibody raised against human Notch $3^{\mathrm{ECD}}$, the 5E1 antibody. The 5E1 monoclonal antibody showed high affinity and specificity to Notch $3^{\mathrm{ECD}}$, crossed the blood-brain barrier, and bound to cerebrovascular Notch $3^{\mathrm{ECD}}$ deposits. Although treatment with 5E1 antibody did not affect the number or surface area of Notch $3^{\mathrm{ECD}}$ deposits nor the presence of white matter lesions, there was a significant improvement in functional hyperemia in CADASIL mutant mice. After completion of the treatment, mutant mice presented cerebral blood flow responses similar to those found in wild-type mice. This suggests that treatment with 5E1 monoclonal antibody modulates cerebrovascular function via a mechanism that is distinct from clearance of Notch $3^{\mathrm{ECD}}$ aggregation, possibly by modulating levels of specific Notch3 species. Future research is needed to characterize the exact nature of this 
underlying mechanism and determine whether normalization of cerebrovascular function improves disease presentation and progression in the longer term. Future studies are also needed to optimize anti-Notch $3^{\mathrm{ECD}}$ antibodies and regimens and replicate these findings in mouse models expressing other CADASIL mutations.

TIMP3 and vitronectin are extracellular matrix proteins found to aggregate with $\operatorname{Notch} 3^{\mathrm{ECD}} \cdot{ }^{47,61}$ Capone et $\mathrm{al}^{61}$ showed that genetic manipulations reducing TIMP3 expression in a CADASIL mouse model restored cerebral blood flow responses, but had no effects on white matter lesions. In contrast, reducing vitronectin expression in the same CADASIL mouse model improved white matter lesions but had no effect on cerebral blood flow. ${ }^{61}$ Interestingly, in both experiments, improvement in cerebrovascular reactivity and white matter lesions was not accompanied by a reduction in Notch $3^{\mathrm{ECD}}$ deposition in brain vessels. This report indicates that manipulating the composition of extracellular aggregates in CADASIL might have a beneficial impact on cerebrovascular function and lesions, but not necessarily through clearance of GOM-Notch $3^{\mathrm{ECD}}$ deposits.

On the basis of the notion that the unpaired number of cysteine residues linked with CADASIL mutations leads to the instability of the Notch $3^{\mathrm{ECD}}$ and the abnormal aggregation of proteins, a cysteine correction approach by EGFR domain exclusion was tested in vitro, using premRNA antisense-mediated skipping of specific NOTCH3 exons. ${ }^{63}$ Although not all exons were eligible for cysteine corrective exon skipping, some harboring common CADASIL-causing mutations, including exon 4 , were found to be eligible. ${ }^{63}$ Corrected Notch3 skip proteins maintained normal processing, ligand binding, and ligandinduced activation properties in vitro. ${ }^{63}$ The in vitro transfection of antisense oligonucleotides in vascular smooth muscle cells of CADASIL patients did not affect cell viability, nor significantly reduced the expression of NOTCH3 or downstream target genes. ${ }^{63}$ However, this study did not assess whether cysteine-corrective NOTCH3 exon skipping influenced GOM aggregation or cerebrovascular disruptions linked to CADASIL. Because cell models do not mimic pathologic hallmarks of CADASIL, such as GOM aggregation and mural cell degeneration, the preclinical efficacy of this approach still needs to be assessed in subsequent in vivo experimental studies. In parallel to this experimental study, a recent report described members of a family carrying the G498C mutation in $\mathrm{NOTCH3}$, a mutation naturally resulting in the skipping of exon 9 and leading to an effective removal of the mutation. ${ }^{64}$ Affected members of this family presented with a mild CADASIL phenotype, characterized by white matter hyperintensity on magnetic resonance imaging (MRI), but no overt disability or cognitive impairment above the age of 60 years. There was no detectable evidence of GOM accumulation in the vessel walls on electron microscopic analysis, but the mutant Notch3 protein had deficient ligand-dependent signaling. Although this case highlights the viability of exon skipping in a naturally occurring system, it also highlights the potential impact of Notch3 signaling as a mechanism contributing to phenotypic expression of CADASIL.

\section{Existing Debate and Diverging Evidence}

Whether GOM-Notch $3^{\mathrm{ECD}}$ aggregation is required for the development of cerebrovascular abnormalities in CADASIL, including mural cell degeneration and cerebrovascular dysfunctions is still unknown. Across studies, there is a lack of direct evidence supporting an association between the presence and quantity of GOM deposits and the severity of mural cell degeneration, white matter lesion, or clinical symptoms. ${ }^{65,66}$ Analysis of vessels from transgenic mice expressing mutant NOTCH3 indicates that degeneration of vascular smooth muscle cells appears before the accumulation of GOM or Notch $3^{\mathrm{ECD}} \cdot{ }^{66}$ Conversely, a different CADASIL mouse model overexpressing high levels of mutant Notch3, the $\operatorname{tgN} 3^{\mathrm{MUT}} 350$ mouse, presented important GOM deposition but failed to develop other central disease features, including mural cell degeneration, basement membrane thickening, or changes in cerebrovascular reactivity and cognition. ${ }^{53,58}$ The apparent lack of robust association between GOM and vessel structural or functional integrity in animal studies might be secondary to limitations of current animal models in accurately replicating the full spectrum of CADASIL pathophysiological mechanisms or of methods to detect and quantify GOM in these models.

A different line of evidence suggesting that mechanisms other than abnormal protein accumulation may play a role in the development of vascular abnormalities in CADASIL comes from numerous reports of patients with $\mathrm{NOTCH} 3$ mutations presenting small-vessel disease in the absence of GOM aggregation..$^{30,41,43,67}$ For instance, Erro et $\mathrm{al}^{68}$ described the case of a patient presenting a nonsense mutation in exon 3 (c.307C $>\mathrm{T}$ ), a genetic variant characterized by a premature stop codon resulting in a truncated protein lacking almost the entire Notch $3^{\mathrm{ECD}}$. The patient presented several classic CADASIL features, including diffuse white matter hyperintensity and cognitive impairment, but did not show GOM deposits on microscopic examination. ${ }^{42,68}$ Other reports of similar cases are described in more detail in the section on Notch 3 loss of function. These mutations are not considered to be CADASIL-causing as they do not result in an odd number of cysteine residues and do not lead to extracellular GOM accumulation. Yet, these observations raise questions as to whether GOM deposits are involved in the pathogenesis of CADASIL or simply represent an epiphenomenon of the disease, and indicate that mechanisms other than GOM aggregation might, fully or partly, underlie cerebrovascular abnormalities associated with certain $\mathrm{NOTCH} 3$ mutations. 


\section{The Role of Aberrant Notch3 Signaling in CADASIL and NOTCH3-Associated Small-Vessel Disease}

\section{Proposed Mechanisms and Supporting Evidence}

Another potential mechanism underlying vascular abnormalities in individuals with $\mathrm{NOTCH} 3$ mutations consists of aberrant Notch3 signaling. The role of Notch3 signaling in the maturation, maintenance, and function of arteries is well established. ${ }^{5,6,9,69,70}$ Notch3 signaling promotes growth and homeostasis of vascular smooth muscle cells and is a critical determinant of their fate, possibly via modulation of platelet-derived growth factor receptor- $\beta$ signaling and apoptosis. ${ }^{69,71,72}$ Considering its crucial role for vascular integrity, it has been hypothesized that dysregulation in Notch3 signaling could be involved in cerebrovascular dysfunction and degeneration in individuals with $\mathrm{NOTCH} 3$ mutations.

Important insights into the significance of Notch3 signaling for cerebrovascular integrity have been obtained from mouse models. Notch3 knockout mice $\left(\operatorname{Notch}^{-1-}\right)$ present important cerebrovascular abnormalities, including structural arterial defects, loss of vascular smooth muscle cells, blood-brain barrier leakage, and altered myogenic tone and cerebrovascular reactivity. ${ }^{6,44,70}$ These mice show increased susceptibility to ischemic strokes, which can be experimentally rescued by the expression of wild-type Notch3 in vascular smooth muscle cells. ${ }^{22,39}$ Notch3 knockout mice display a progressive degeneration of mural cells, with evidence of apoptosis and large gaps in mural cell coverage in vessels from the brain and the retina. ${ }^{73}$ The expression of wild-type Notch3 in these mice was found to rescue mural cell degeneration. ${ }^{73}$ In contrast, expression of the C455R mutant receptor, a mutation affecting the ligandbinding domain of Notch3 and leading to hypomorphic signaling, was not able to rescue vascular degeneration. A different study in mutant mice with inhibited canonical Notch signaling in vascular smooth muscle cells found significant defects in patterning of the cerebral vasculature, including in the circle of Willis and cerebral arteries. ${ }^{74}$ This study further corroborated that mice harboring a null mutation in the Notch3 receptor presented a lower mass of smooth muscle cells within arteries, supporting a link between the absence of Notch3 signaling and loss of mural cells. ${ }^{74}$ Together, these findings support a direct link between Notch3 signaling and cerebrovascular integrity. Interestingly, cerebrovascular abnormalities reported in Notch3 knockout mice align with those found in mice expressing CADASIL mutations in $\mathrm{NOTCH3}$, except for the loss of mural cells, a feature that is prominent in NOTCH3 knockout mice but not consistently observed in CADASIL mouse models. $^{5-7,73}$

Mouse embryonic fibroblasts expressing homozygous combinations of the C455R or R1031C mutated CADASIL alleles show significant reduction in the activity of the
Notch3 receptor compared with those expressing heterozygous mutant alleles, suggesting a link between the expression level of the mutant receptor and Notch3 signaling. ${ }^{22}$ Furthermore, mice carrying the C455R mutant allele, a mutation associated with a particularly severe phenotype and an earlier onset of strokes, displayed a greater reduction in Notch3 signaling than those carrying the R1031C allele. $^{22,75}$ This finding supports an association between phenotypic severity and Notch3 signaling. However, other studies investigating the effect of different CADASIL mutations on Notch3 activity point to more complex findings. ${ }^{76-78}$ For instance, transgenic mice expressing the C428S NOTCH3 mutation on EGFR 10 showed impaired Notch3 function, whereas transgenic mice harboring mutations within EGFR 1 to 6 did not. ${ }^{78}$ More recently, mice carrying the archetypal R169C CADASIL mutation were shown to exhibit an increase in Notch3 activity and a reduction in vascular lumen diameter, a pathophysiological feature associated with greater stroke susceptibility. ${ }^{40} \mathrm{Ge}-$ netic manipulations to reduce Notch3 activity in these mice prevented the reduction in arterial lumen diameter without influencing GOM deposition, suggesting a pathogenic role of the increased Notch3 activity in this model. ${ }^{40}$ Taken together, these studies indicate that, although certain mutations appear to leave Notch3 signaling unaffected, others seem to promote cerebrovascular abnormalities via a reduction or even an increase in Notch3 signaling. These divergent findings raise the possibility that distinct NOTCH3 mutations exert a differential effect on Notch3 signaling and alter cerebrovascular integrity through distinct mechanisms. Reports of both hypomorphic and hypermorphic Notch3 activity in models with NOTCH3 mutations can be interpreted in the context of a signaling threshold model (or goldilocks). Such models, which have been used in the context of other diseases, including cancer $^{79}$ and Kabuki syndrome, ${ }^{80}$ posit that either too much or too little signaling can lead to pathologic states. It is also important to note that, to this date, the effect of NOTCH3 mutations on Notch3 signaling has only been systematically investigated in a small proportion of all reported CADASIL mutations. Furthermore, current experimental assays and models might be limited in their ability to detect or reproduce subtle signaling abnormalities that might still be relevant for pathophysiological changes associated with $\mathrm{NOTCH} 3$ mutations.

Another important line of evidence supporting the relevance of Notch3 signaling comes from several case studies on patients with cerebrovascular abnormalities and NOTCH3 mutations leading to Notch3 loss of function. Pippucci et $\mathrm{al}^{67}$ described a young patient with a rare homozygous c.C2898A (p.C966*) null mutation in NOTCH3, eliminating Notch3 expression and causing important Notch3 signaling impairment. The patient presented a severe arteriopathy with an early-onset cavitating leukoencephalopathy. At the age of 24 years, the patient was aphasic and dysphagic, and unable to walk independently. Two 
siblings from a consanguineous family carrying a homozygous nonsense mutation within the EGFR 19 of NOTCH3 had a loss of function in Notch $3 .^{81}$ The two siblings presented a history of childhood-onset strokes, mild cognitive impairment, hemiparesis, mobility impairment, pseudobulbar palsy, and unmotivated laughing. On MRI examination, both siblings presented diffuse white matter hyperintensity and multiple lacunar infarctions. These unique case reports strongly suggest that drastic Notch3 loss of function leads to cerebral small-vessel disease and an ischemic phenotype.

Less drastic bona fide loss-of-function mutations in NOTCH3, including premature stop codons and frameshift deletion, have also been reported in heterozygous patients presenting an inherited small-vessel disease syndrome. ${ }^{10,41,67,68,82-85}$ A family with two members presented a heterozygous NOTCH3 mutation in exon 18 associated with a frameshift and a premature stop codon within EGFR 24. ${ }^{86}$ The father, aged 69 years and presenting cardiovascular risk factors, had no history of migraines, strokes, or neurologic deficits, but presented extensive white matter hyperintensity on MRI, lacunar infarcts, and cognitive impairment. At the age of 37 years, the daughter, also carrying the mutation, presented with a history of migraines, dizziness, and bilateral subcortical white matter hyperintensity. Bentley et $\mathrm{al}^{82}$ described a family with a heterozygous missense $\mathrm{C} 212 \mathrm{Y}$ mutation in exon 4 of NOTCH3, within the EGFR 5. In vitro analysis showed that the mutation resulted in defective Notch3 nuclear signaling. The affected mother, in her 50s, presented a history of recurrent ischemic strokes and transient ischemic attacks, migraines, and cognitive impairment. The two daughters carrying the mutation, in their $20 \mathrm{~s}$ and early $30 \mathrm{~s}$, presented a history of migraines. On MRI examination, all of them showed extensive and confluent white matter hyperintensity affecting the temporal poles and external capsules, a neuroimaging profile consistent with CADASIL. For many of these reported cases, NOTCH3 loss-of-function mutations appear to promote cerebral small-vessel disease and follow an autosomal-dominant mode of transmission, despite the absence of GOM accumulation. The clinical similarities between patients with NOTCH3 loss-of-function mutations and those with classic CADASIL-causing mutations can be striking and suggest the presence of at least some shared pathologic mechanisms.

It has previously been argued that NOTCH3 loss-offunction mutations are nondisease causing. ${ }^{30,86}$ For instance, Rutten et $\mathrm{al}^{30}$ described two brothers from the Netherlands with a NOTCH3 loss-of-function mutation (c.307C $>$ T). One brother had mild MRI abnormalities, polyneuropathy, migraine with aura, and recurrent ischemic strokes at the ages of 50 and 52 years, but no evidence of GOM on skin biopsy. Despite carrying the same mutation, his 50-year-old brother experienced migraines but presented an unremarkable MRI and had no history of stroke or cognitive impairment. This led the authors to conclude that
NOTCH3 loss-of-function mutations do not play a significant role in the pathophysiology of CADASIL. However, a few years later, Moccia et $\mathrm{al}^{41}$ described an Italian family affected by the same mutation in NOTCH3. Family members carrying the mutation presented with progressive parkinsonism, cognitive impairment, a family history of early stroke, and extensive subcortical and periventricular white matter hyperintensities on MRI, but with no evidence of GOM on skin biopsy. The same mutation causing a CADASIL-like phenotype in a man from the Netherlands and in multiple members of an Italian family strongly suggests the pathogenicity of such mutation. Although clinically informative and hypothesis-generating, findings stemming from individual case reports need to be interpreted with caution: case studies are limited in their generalizability and do not allow inferring causality. The absence of GOM on examination in some of these patients could also be the result of methodological limitations hindering their detection. Conclusions originating from case studies need to be assessed and confirmed experimentally.

Converging evidence shows that cysteine-affecting NOTCH3 mutations in the ligand-binding domain EGFR 10 to 11 lead to both GOM accumulation and defective Notch3 receptor function, possibly by impeding Jagged1induced signaling activity. ${ }^{22,76-78}$ Reports on the phenotypic expression associated with such mutations have been mixed. Individuals carrying the $\mathrm{C} 455 \mathrm{R}$ mutation within the EGFR 10 present severely reduced ligand-induced Notch3 signaling and a particularly severe cerebral small-vessel disease phenotype, characterized by an earlier onset of stroke and widespread MRI abnormalities. ${ }^{22,75}$ Yet, these individuals maintained a relatively well-preserved cognitive and functional status more than two decades after the onset of strokes. ${ }^{75}$ A phenotype characterized by milder cognitive deficits, lower lacunar infarct volume, and higher volume of white matter hyperintensity has been described. ${ }^{78,87}$ More recently, investigation of a French Canadian family with a NOTCH3 mutation on EGFR 11 revealed an important variability in the clinical severity of affected family members, suggestive of a variable mutation penetrance. ${ }^{88}$ The broad clinical spectrum found in these patients raises the possibility that hypomorphic $\mathrm{NOTCH} 3$ mutations have a variable penetrance, leading to an increased phenotypic heterogeneity. These findings align with recent evidence demonstrating that individuals harboring cysteine-altering CADASIL mutations located in EGFR 7 to 34, outside of the classic mutational hotspot, can remain asymptomatic for decades. ${ }^{10,11,87}$ Although their clinical presentation appears notably less severe than that of individuals carrying cysteine-affecting NOTCH3 mutations within EGFR 1 to 6, other reports indicate that individuals carrying common NOTCH3 sequence variants within EGFR domains 7 to 34 present more severe neuroimaging markers of small-vessel disease and a higher risk of strokes when compared with control subjects. ${ }^{12,89,90}$ Collectively, these findings support heterogeneity in the penetrance and severity of small-vessel 
disease phenotypes associated with NOTCH3 mutations, ranging from nonpenetrant to a CADASIL-like syndrome. ${ }^{11}$ Considering the relatively high prevalence of $\mathrm{NOTCH3}$ mutations or variants in the general population, these findings also highlight their potential influence on milder forms of small-vessel disease.

Supporting the role of abnormal Notch3 signaling in cerebrovascular abnormalities, Fouillade et $\mathrm{al}^{43}$ reported the case of a 53-year-old woman with a cysteine-sparing NOTCH3 heterozygous missense mutation (c.4544T $>$ C) in exon 25. This mutation does not target an EGFR nor leads to the deposition of GOM and, thus, is not viewed as CADASIL-causing. Yet, the patient presented with a history of migraine with aura, widespread symmetrical white matter hyperintensity on MRI, and a family history suggestive of strokes and dementia. Transcriptional activation assays of the mutant receptor demonstrated a ligand-independent increase in canonical Notch3 signaling. ${ }^{43}$ These findings invoke the possibility of Notch3 signaling hyperactivation as another potential pathogenic mechanism underlying small-vessel disease.

Consideration of currently available genetic data indicates that NOTCH3 has a relatively high probability of being haploinsufficient in humans, meaning that a single functional NOTCH3 allele may not be sufficient to maintain normal function. On the basis of data from the gnomAD database, ${ }^{91} \mathrm{NOTCH} 3$ has an estimated 0.41 probability of being loss of function intolerant, as the database was expected to find about 97 loss-of-function variants in a data set of $>200,000$ genomes, but found only 22 . As a reference, the probability of being loss of function intolerant score for NOTCH4 is 0 because loss-of-function mutations are not constrained by evolution for this gene, whereas the score for both NOTCH1 and NOTCH2 is 1 because loss-of-function mutations are almost never tolerated, consistent with their more widespread expression relative to NOTCH3. Similar results are obtained when using the observed/expected score, an additional and more robust measure of gene constraint, with low values indicating strong intolerance to loss of function. For NOTCH3, the observed/expected score is $0.23(90 \% \mathrm{CI}, 0.16-0.32)$, which is below the hard threshold of $<0.35$ for genes under selection against loss-offunction variants. Only $23 \%$ of the expected loss-offunction variants for NOTCH3 were observed, suggesting strong selection against loss-of-function variants. As reference, the observed/expected scores for NOTCHI and NOTCH2 are 0.05 (CI, 0.02-0.1) and 0.06 (CI, 0.03-0.12), respectively, meaning they are also constrained, whereas for NOTCH4, the observed/expected score is 0.59 (CI, $0.47-0.74)$, meaning it is not constrained. This indicates that NOTCH3 loss-of-function variants observed in humans with small-vessel disease phenotypes are unlikely to be neutral polymorphisms, notwithstanding issues of gene penetrance and expressivity.

In sum, human genetic data suggest that NOTCH3 mutations resulting in aberrant Notch3 signaling can be associated with small-vessel abnormalities and CADASILlike phenotypes, even in the absence of GOM-Notch $3^{\text {ECD }}$ accumulation. Findings from human case studies intersect with those stemming from mouse models in suggesting that distinct $\mathrm{NOTCH} 3$ mutations might exert a differential effect on Notch3 signaling, with some mutations leading to unaffected, hyperactive, or hypoactive signaling. It is possible that, depending on the mutation type and location, NOTCH3 mutations promote vascular abnormalities through different mechanisms. It is important to stress herein that bona fide NOTCH3 loss-of-function or cysteine-sparing mutations are typically not considered to be CADASIL causing because individuals with these mutations do not present GOM on microscopic tissue examination, a feature considered central to the diagnosis of CADASIL. ${ }^{30}$ Reserving a diagnosis of CADASIL for individuals with canonical cysteine-altering NOTCH3 mutations that trigger GOM aggregation might be helpful in the future for the development of mechanismspecific therapies. Yet, if such distinction is to prevail, it is important to agree on a term that encompasses the growing number of reports describing patients experiencing inherited small-vessel disease associated with NOTCH3 mutations that do not affect cysteine residues nor lead to GOM accumulation. We herein propose that the term NOTCH3associated small-vessel disease could serve this purpose.

\section{Therapeutic Implications and Preliminary Evidence}

If Notch3 signaling plays a critical role in the emergence of small-vessel disease or, alternatively, acts as a disease modifier in patients with specific NOTCH3 mutations, then therapeutic interventions aiming to normalize Notch3 signaling could modify, prevent, and/or delay disease progression.

In vitro experiments evaluated the therapeutic potential of a Notch3 agonist antibody. The monoclonal antibody A13 is specific to the Notch3 receptor's negative regulatory region, ${ }^{73,92}$ specifically recognizes human Notch3, and shows no cross-reactivity to mouse Notch3, human Notch1, or human Notch2. ${ }^{73,92}$ The A13 binds a linear epitope in Lin12/ Notch repeat-1 under native and denaturing conditions and activates Notch 3 by perturbing the interaction of Lin12/Notch repeat-1 and heterodimerization domain- $2 .{ }^{92}$ The A13 antibody activates Notch3 independently from the presence of ligands driving the expression of transcriptional targets.

The C455R mutation in NOTCH3 results in both a strong abrogation of Notch3 signaling and GOM accumulation within the vessel wall in both humans and mice carrying the mutation, ${ }^{22,75}$ two proposed pathophysiological mechanisms underlying small-vessel abnormalities in CADASIL. The effect of the A13 agonist antibody was tested in vitro in isogenic human embryonic kidney cell lines expressing the human Notch3 receptor (wild type or C455R mutant) and in cells expressing the human Jagged1 ligand under the regulation of a tetracycline-inducible promoter. ${ }^{73}$ The A13 antibody induced the activation of both the wild-type and 
C455R mutant Notch3 receptor. These results demonstrate that the A13 antibody effectively activates the Notch3 receptor, even in the presence of a mutation known to impair Jagged1-induced signaling, confirming that the antibody works via a noncompetitive mechanism. Treatment of cells expressing wild-type and/or mutant C455R Notch3 with the A13 agonist antibody led to a robust increase in Notch $3^{\mathrm{ECD}}$ in the cell culture supernatant. As expected, treatment with a $\gamma$-secretase inhibitor compound E reduced Notch3 signaling mediated by the A13 antibody but had no effect on levels of Notch $3^{\mathrm{ECD}}$ released into the supernatant. More importantly, Notch3 signaling, measured using a gene reporter assay, was significantly and strongly correlated with levels of Notch $3^{\mathrm{ECD}}$ in the cell culture supernatant, suggesting that the antibody treatment led to Notch $3^{\mathrm{ECD}}$ release in the supernatant through modulation of Notch3 signaling.

The preclinical efficacy of the A13 agonist antibody was further assessed in mice carrying the C455R mutation in NOTCH $3 .^{73}$ These mice typically show progressive mural cell loss and degeneration. ${ }^{22}$ A 5-week treatment with the A13 agonist antibody doubled mural cell coverage of retinal arterioles in 6-week-old mice. ${ }^{73}$ Antibody penetration across the blood-retinal barrier and into the central nervous system was demonstrated using perfusion with a fluorescently labeled A13 antibody. ${ }^{73}$ Target engagement was confirmed by immunohistology, showing increased levels of transcriptionally active cleaved Notch3 intracellular domain using the V1662 antibody (Genentech, South San Francisco, CA) and by increased levels of Notch $3^{\mathrm{ECD}}$ in the plasma, measured via an in-house enzyme-linked immunosorbent assay. ${ }^{73,93}$ These results suggest that inducing Notch3 signaling in mural cells is effective in preventing mural cell loss in C455R mutant mice, a finding that provides critical proof-of-concept demonstration of the feasibility and efficacy of our approach. It is also noteworthy that the use of this Notch3 agonist antibody may allow tackling both hypothesized pathologic mechanisms contributing to NOTCH3-associated small-vessel disease and CADASIL by simultaneously modulating Notch3 signaling and promoting clearance of Notch $3^{\mathrm{ECD}}$. Direct experimental investigation of this possibility is now warranted.

\section{Existing Debate and Diverging Evidence}

There has been much debate on the significance of Notch3 loss of function and signaling as a cause for small-vessel abnormalities associated with $\mathrm{NOTCH} 3$ mutations.

Experimental studies in mouse models casted early doubts on the relevance of Notch3 signaling as a factor contributing to the pathophysiology of CADASIL. Although homozygous Notch3 knockout mice (Notch $3^{-/}$) develop significant postnatal defects in mural cell maturation and arterial function, ${ }^{5-7,70}$ they do not develop characteristic accumulation of GOM in the vasculature. ${ }^{94}$ In addition, previous studies concluded that eliminating the expression of wild-type Notch3 in wild-type or CADASIL mutant mice did not exacerbate white matter degeneration. ${ }^{95,96}$ These findings have been interpreted as evidence that Notch3 signaling is not sufficient to account for CADASIL phenotypic characteristics. Another line of contradicting evidence comes from multiple reports of preserved Notch3 signaling in mouse models carrying CADASIL mutations located in the mutational hotspot EGFR 1 to $6 .^{76,77,95,97}$ The preserved Notch3 activity associated with several common CADASIL mutations was further corroborated by in vitro studies showing that mutated Notch3 receptors retain normal cell surface expression, ligand binding, and signaling properties. ${ }^{98,99}$ On the basis of these findings, it has been proposed that CADASIL-causing mutations do not impair Notch3 signaling and that the small-vessel disease pathology in CADASIL is instead linked to a neomorphic or toxic effect associated with the abnormal accumulation of GOMNotch $3^{\mathrm{ECD}}$. $^{21}$

The progressive nature of CADASIL is a factor potentially contributing to inconsistencies in findings related to Notch3 activity. Hypomorphic Notch3 activity becomes critical at a more advanced age and may not be detectable in younger mice harboring the R1031C CADASIL mutations. ${ }^{22}$ Evidence of white matter degeneration also appears at a later stage in CADASIL mouse models. For instance, in a mouse model with the archetypal R169C CADASIL mutation, the vacuolation of white matter tracts is observable at approximately 20 months. ${ }^{96}$ The later appearance of vascular abnormalities in CADASIL mouse models is consistent with the adult onset of symptoms in most patients with CADASIL. ${ }^{1,2}$ Therefore, studies examining younger mice may have failed to detect signaling abnormalities associated with $\mathrm{NOTCH} 3$ mutations or to observe vascular abnormalities linked to Notch3 deficiency. It is also possible that discrepancies in findings are linked to differences in the investigation of vascular integrity in these models or that the phenotype is nonuniform, with some NOTCH3 mutant mouse models presenting vessels with normal mural cell coverage and others completely devoid of it. ${ }^{6,7,16,22}$ Finally, available animal models and ligand-dependent assays are limited in their ability to accurately capture the effect of different mutations on the activity of the Notch3 receptor. For instance, a previous report concluded that the archetypal R169C mutation had no effect on Notch3 signaling and that signaling was not related to pathology. ${ }^{96}$ Years later, the same research group demonstrated that a mouse model carrying the same mutation presented an increase in Notch3 signaling, which, in turn, was related to pathologic features. ${ }^{40}$ The development and validation of more sensitive methods or models to explore canonical and noncanonical signaling pathways might allow uncovering signaling abnormities not previously detected. Also possibly reconciling seemingly conflicting conclusions, growing evidence now indicates that distinct $\mathrm{NOTCH} 3$ mutations may exert a differential effect on Notch3 processing and signaling activity, with mutations in or near the ligand-binding domain 
(EGFR 10 to 11) leading to a reduced signaling and other mutations leading to a preserved or increased activity. ${ }^{76-78}$

Historically, the notion that NOTCH3 loss-of-function mutations could play a role in small-vessel disease lacked widespread acceptance because reports of clinically affected individuals carrying such mutations were scarce. Over time, many cases and families carrying bona fide NOTCH3 lossof-function mutations have been described, including clear evidence of dosage effects, with homozygote mutation carriers presenting more severe disease than heterozygotes carriers. ${ }^{41,67,81,82,86}$ Yet, the small-vessel disease phenotype described in individuals with bona fide NOTCH3 loss-offunction mutations appears more variable and often milder than that of many CADASIL patients..$^{11,30,87}$ This observation brings up the mechanistic question as to why loss-offunction mutations might lead to a milder and more variable clinical presentation than point mutations impacting cysteine residues at particular locations of the Notch3 receptor. It is possible that the intravascular accumulation of GOM associated with cysteine-affecting mutations confers toxic effects that contribute to disease pathophysiology and exacerbate its severity. It is also conceivable that cysteinealtering mutations result in dominant negative effects that diminishes Notch3 signaling. ${ }^{46}$ This highly relevant knowledge gap that needs to be addressed experimentally. Comprehensive efforts are also needed in the field of CADASIL to systematically and adequately characterize Notch3 function across all reported NOTCH3 mutations, as to determine the frequency and extent of signaling abnormalities-associated theses mutations. Such efforts have been informative in related fields, including familial Alzheimer disease due to PSENI mutations. ${ }^{100}$ However, the broad characterization of Notch3 function across mutations first relies on the validation and optimization of assays, allowing the detection of subtle Notch3 signaling abnormalities that might be of pathophysiological relevance.

\section{Discussion}

On the basis of a wealth of experimental, clinical, and genetic studies, it appears that NOTCH3 mutations can lead to a variable phenotype of cerebral small-vessel disease. The spectrum of small-vessel disease associated with $\mathrm{NOTCH3}$ mutations can be regrouped under the umbrella of NOTCH3-associated small-vessel disease, a term herein proposed as a way to encompass both classic CADASIL cysteine-altering $\mathrm{NOTCH} 3$ mutations and $\mathrm{NOTCH} 3$ mutations not traditionally viewed as CADASIL causing. In some cases, they lead to an inherited small-vessel disease phenotype of variable severity. Specifically, the current review of the literature suggests that NOTCH3 mutations leading to small-vessel disease can be regrouped into at least three categories.

The first category corresponds to classic CADASIL NOTCH3 mutations impacting the number of cysteine amino acids in one of the EGFRs of the Notch3 receptor's extracellular domain (Notch $3^{\mathrm{ECD}}$ ), with mutations affecting the EGFR 1 to 6 seemingly resulting in a more severe clinical phenotype. ${ }^{10,11,18,87}$ The pathologic hallmarks of these classic CADASIL mutations not only include the degeneration of mural cells and other vascular abnormalities, but also the accumulation of GOM in vessel wall. Growing evidence demonstrates that GOM contains several proteins, including the Notch $3^{\mathrm{ECD}} \cdot{ }^{22,33-35}$ Hence, it has been hypothesized that the primary mechanism of action for these CADASIL-causing mutations consists of a toxic gain of function, or neomorphic activity, leading to protein misfolding and associated with the abnormal accumulation of Notch $3^{\mathrm{ECD}}$ as well as other proteins within the vasculature. ${ }^{21,101}$ Although it has been argued that classic CADASIL NOTCH3 mutations do not affect Notch3 signaling, current evidence suggests that mutations in or near the ligand-binding domain of Notch3 (EGFR 10 to 11) can result in loss of function. At least one CADASIL-causing mutation, the R169C mutation located in the mutational hotspot (EGFR 1 to 6), was recently shown to lead to Notch3 hyperactivation. ${ }^{40}$ These findings indicate that CADASIL NOTCH3 mutations differ with respect to their consequences on signaling activity. Yet, CADASIL NOTCH3 mutations might not represent the full spectrum of NOTCH3 mutations promoting the emergence of smallvessel disease, and other mutations on the NOTCH3 gene, some of which result in compromised Notch 3 function, also promote cerebral small-vessel disease.

The second category consists in NOTCH3 loss-of-function mutations, including premature stop codons and frameshift deletion. These mutations are typically not considered to be CADASIL-causing because they do not trigger GOM aggregation and do not involve cysteine residues in one of the EGFRs. Yet, a review of numerous case studies suggests that NOTCH3 loss-of-function mutations can nonetheless lead to an inherited small-vessel disease phenotype, sharing similarities with CADASIL, but of variable severity or penetrance. ${ }^{41,42,67,83,84}$ The last category consists of NOTCH3 hyperactivation mutations. This category is not as well documented and mainly stems from the description of a family with a cysteine-sparing $\mathrm{NOTCH} 3$ missense mutation (p.L1515P) leading to the receptor's hyperactivation via destabilization of the Notch3 negative regulatory region located between the LNR repeats and the transmembrane domain. ${ }^{43}$ Family members carrying the mutation present with inherited cerebral small-vessel disease, without GOM accumulation. It is important to mention that other cysteinesparing NOTCH3 mutations have also been described in the literature, with evidence that, at least some of them, lead to CADASIL-like features, including white matter lesion, migraine, increased stroke susceptibility, and GOM accumulation. ${ }^{23}$ Yet, it appears that only a proportion of these mutations lead to GOM aggregation, and Notch3 signaling activity has rarely been investigated in these mutations. Future studies should aim to clarify pathophysiological 
mechanisms underlying vascular abnormalities in individuals with cysteine-sparing NOTCH3 missense mutations in the presence or absence of GOM deposits.

To summarize, available evidence indicates that NOTCH3 mutations leading to toxic gain of function, loss of function, and hyperactivation can cause small-vessel disease in humans, regardless of the type of mutation or whether GOM deposition is present. On the basis of this observation, it can be hypothesized that Notch 3 signaling functions as a signaling threshold (or Goldilocks) pathway in the context of small-vessel disease, where either too much or too little signaling promotes mural cell degeneration through downstream effects on the expression of genes and proteins relevant to cell survival (Figure 3). This hypothetical model is based on previously published experimental findings exploring the effects of Notch3 signaling inhibition and hyperactivation on downstream gene expression and cell survival. $^{16}$ Experiments in primary mural cell cultures showed that ligand-mediated induction of Notch3 signaling by 10 - to 12 -fold protected mural cells from apoptotic triggers. In contrast, hypoactivation or hyperactivation of Notch3 signaling via experimental manipulations led to pericyte degeneration and death via apoptosis. Eight genes were found to consistently respond to both hypoactive and hyperactive Notch3 signaling, including Jagged1, Heyl, Hey1, Hey2, PCSK6, TESC, HMOX1, and Tnfrs10a. These genes are shown in the middle panel (Figure 3B) under the physiological signaling label, and their expression is assumed to be involved in promoting mural cell survival. Nine genes were found to specifically respond to hypoactive Notch3 signaling, and nine other genes were found to respond to hyperactive signaling (Figure 3B). These genes are potentially involved in modulating cellular degeneration and apoptosis in the context of Notch3 hypoactive or hyperactive states. These results corroborate the critical role of Notch3 signaling in the regulation of mural cell fate and apoptosis under a signaling threshold model. Although further validation of this hypothetical model is required, this hypothesis is consistent with insights previously published by Braune and Lendahl, ${ }^{79}$ suggesting that dysregulated Notch signaling can lead to disease states.

Notch3 signaling normalization can represent a useful therapeutic target for $\mathrm{NOTCH} 3$-associated small-vessel disease. However, this focus on signaling by no means implies that the accumulation of GOM-Notch $3^{\mathrm{ECD}}$ in CADASIL is not relevant to its pathophysiology. These hypotheses are not mutually exclusive, and in some cases, the same mutation may operate via combined mechanisms. For instance, the C455R CADASIL mutation, a mutation characterized by an earlier onset of strokes, leads to both Notch3 loss of function and GOM accumulation. ${ }^{22,75}$ It is also possible that Notch3 signaling acts as a modulator of disease susceptibility, by influencing the risk for small-vessel disease. The validity of these hypotheses needs to be investigated experimentally. There is an important need for the optimization of experimental models and methods to obtain highly sensitive and

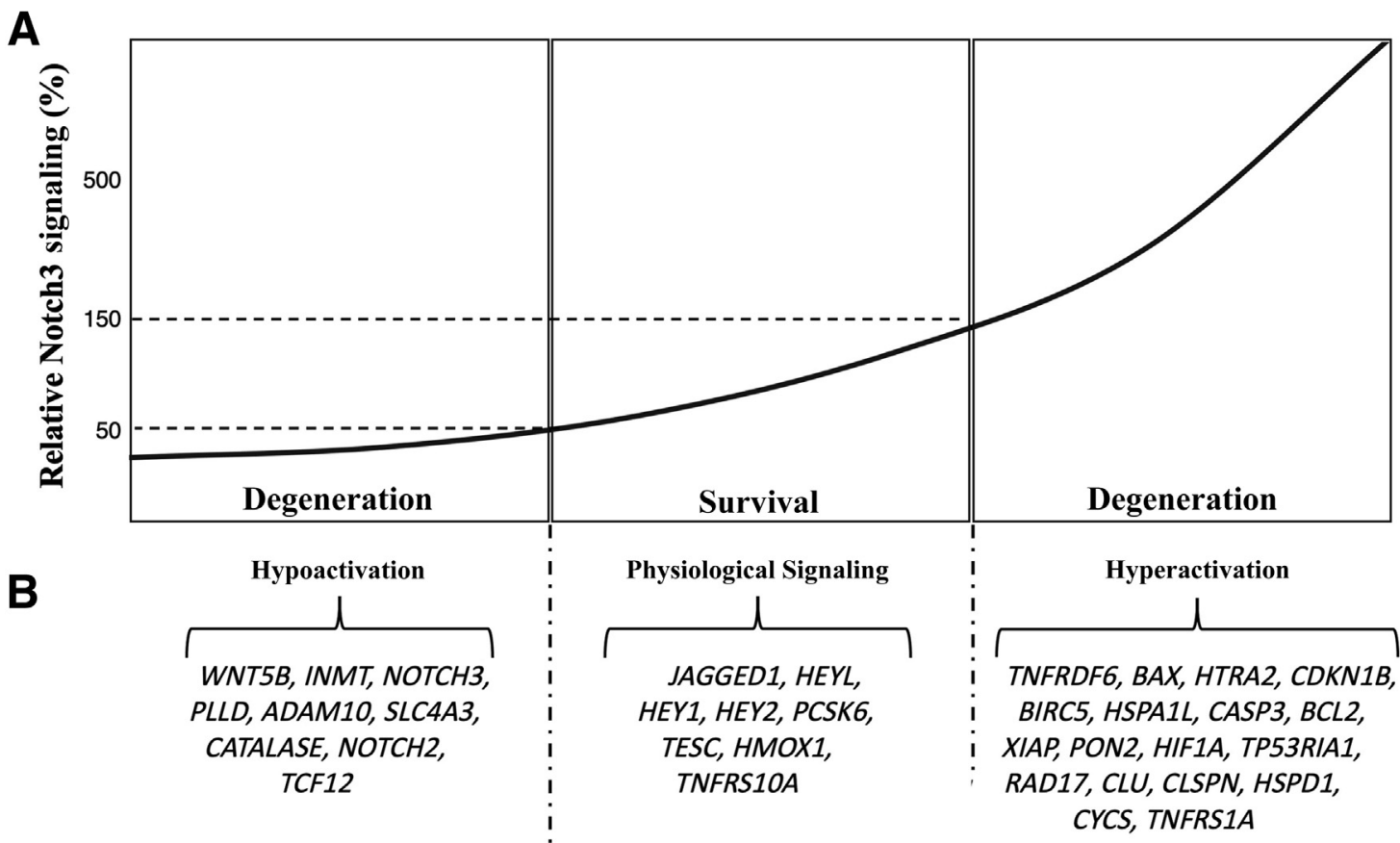

Figure 3 Notch3 signaling thresholds model. A: Hypothetical model of the Notch3 signaling Goldilocks based on previously published analysis of the effect of Notch3 hypoactivation and hyperactivation on mural cell survival. States of hypoactivation or hyperactivation in Notch3 signaling were associated with mural cell degeneration and apoptosis (Arboleda-Velasquez et $\mathrm{al}^{16}{ }^{16}$ ). The optimal level of Notch3 signaling, associated with a state of cell survival, is illustrated by dashed lines. B: Candidate genes found to be specifically responsive to each signaling state of the Notch3 Goldilocks are listed (ArboledaVelasquez et $\mathrm{al}^{16}{ }^{16}$. 
specific measurements of Notch3 signaling and aggregation. Because these cases have captured the attention of medical researchers, past clinical research has mostly focused on cysteine-affecting NOTCH3 mutations within EGFR 1 to 6, leading to the severe and classic CADASIL phenotype. Future studies are now needed to systematically characterize clinical manifestations and pathophysiological characteristics associated with cysteine-affecting NOTCH3 mutations outside of the mutational hotspot for CADASIL, including mutations affecting the ligand-binding domain of Notch3 and leading to abnormal signaling activity, as well as with other types of NOTCH3-associated small-vessel disease.

Findings summarized in this review suggest that NOTCH3 mutations exert a differential influence on Notch3 signaling and might influence the risk of small-vessel disease through distinct, but possibly convergent, pathophysiological mechanisms. Aberrant Notch3 signaling and abnormal protein aggregation in GOM are two mechanisms possibly contributing to the pathophysiology and clinical presentation of individuals with $\mathrm{NOTCH} 3$ mutations and small-vessel disease. Further proof of the validity of these hypotheses necessitates the systematic examination of their therapeutic values, and future studies are needed to assess the preclinical utility of hypothesis-driven therapeutics targeting these mechanisms. With recent evidence highlighting the higher than previously estimated prevalence of NOTCH3 mutations and variants, as well as their potential role in promoting cerebral small-vessel disease, such therapies could allow reducing the burden of strokes or vascular cognitive impairment in the population.

\section{Acknowledgments}

We thank Drs. Yakeel Quiroz (Massachusetts General Hospital, Boston, MA) and Diego Sepulveda-Falla (Institut für Neuropathologie Universitätsklinikum HamburgEppendorf, Hamburg, Germany) for kindly providing images included in this review (Figure 2).

\section{References}

1. Chabriat H, Joutel A, Dichgans M, Tournier-Lasserve E, Bousser MG: Cadasil. Lancet Neurol 2009, 8:643-653

2. Joutel A, Corpechot C, Ducros A, Vahedi K, Chabriat H, Mouton P, Alamowitch S, Domenga V, Cécillion M, Maréchal E: Notch3 mutations in CADASIL, a hereditary adult-onset condition causing stroke and dementia. Nature 1996, 383:707-710

3. Opherk C, Peters N, Herzog J, Luedtke R, Dichgans M: Long-term prognosis and causes of death in CADASIL: a retrospective study in 411 patients. Brain 2004, 127:2533-2539

4. Bersano A, Bedini G, Oskam J, Mariotti C, Taroni F, Baratta S, Parati EA: CADASIL: treatment and management options. Curr Treat Options Neurol 2017, 19:31

5. Domenga V, Fardoux P, Lacombe P, Monet M, Maciazek J, Krebs LT, Klonjkowski B, Berrou E, Mericskay M, Li Z: Notch3 is required for arterial identity and maturation of vascular smooth muscle cells. Genes Dev 2004, 18:2730-2735
6. Henshall TL, Keller A, He L, Johansson BR, Wallgard E, Raschperger E, Mäe MA, Jin S, Betsholtz C, Lendahl U: Notch3 is necessary for blood vessel integrity in the central nervous system. Arterioscler Thromb Vasc Biol 2015, 35:409-420

7. Liu H, Zhang W, Kennard S, Caldwell RB, Lilly B: Notch3 is critical for proper angiogenesis and mural cell investment. Circ Res 2010, 107:860-870

8. Wang T, Baron M, Trump D: An overview of Notch3 function in vascular smooth muscle cells. Prog Biophys Mol Biol 2008, 96: 499-509

9. Iso T, Hamamori Y, Kedes L: Notch signaling in vascular development. Arterioscler Thromb Vasc Biol 2003, 23:543-553

10. Rutten JW, Dauwerse HG, Gravesteijn G, van Belzen MJ, van der Grond J, Polke JM, Bernal-Quiros M, Lesnik Oberstein SA: Archetypal NOTCH3 mutations frequent in public exome: implications for CADASIL. Ann Clin Transl Neurol 2016, 3:844-853

11. Rutten JW, Hack RJ, Duering M, Gravesteijn G, Dauwerse JG, Overzier M, van den Akker EB, Slagboom E, Holstege H, Nho K: Broad phenotype of cysteine-altering NOTCH3 variants in UK Biobank: CADASIL to nonpenetrance. Neurology 2020, 95: e1835-e1843

12. Hack RJ, Rutten JW, Person TN, Li J, Khan A, Griessenauer CJ, Center RG, Abedi V, Lesnik Oberstein SA, Zand R: Cysteine-altering $\mathrm{NOTCH} 3$ variants are a risk factor for stroke in the elderly population. Stroke 2020, 120:030343

13. Joutel A, Monet-Leprêtre M, Gosele C, Baron-Menguy C, Hammes A, Schmidt S, Lemaire-Carrette B, Domenga V, Schedl A, Lacombe P: Cerebrovascular dysfunction and microcirculation rarefaction precede white matter lesions in a mouse genetic model of cerebral ischemic small vessel disease. J Clin Invest 2010, 120: $433-445$

14. Joutel A, Andreux F, Gaulis S, Domenga V, Cecillon M, Battail N, Piga N, Chapon F, Godfrain C, Tournier-Lasserve E: The ectodomain of the Notch3 receptor accumulates within the cerebrovasculature of CADASIL patients. J Clin Invest 2000, 105: 597-605

15. Villa N, Walker L, Lindsell CE, Gasson J, Iruela-Arispe ML, Weinmaster G: Vascular expression of Notch pathway receptors and ligands is restricted to arterial vessels. Mech Dev 2001, 108:161-164

16. Arboleda-Velasquez JF, Primo V, Graham M, James A, Manent J, D'Amore PA: Notch signaling functions in retinal pericyte survival. Invest Ophthalmol Vis Sci 2014, 55:5191-5199

17. Sweeney C, Morrow D, Birney YA, Coyle S, Hennessy C, Scheller A, Cummins PM, Walls D, Redmond EM, Cahill PA: Notch 1 and 3 receptors modulate vascular smooth muscle cell growth, apoptosis and migration via a CBF-1/RBP-Jk dependent pathway. FASEB J 2004, 18:1421-1423

18. Rutten JW, Haan J, Terwindt GM, Van Duinen SG, Boon EM, Lesnik Oberstein SA: Interpretation of NOTCH3 mutations in the diagnosis of CADASIL. Expert Rev Mol Diagn 2014, 14:593-603

19. Dichgans M, Ludwig H, Müller-Höcker J, Messerschmidt A, Gasser T: Small in-frame deletions and missense mutations in CADASIL: 3D models predict misfolding of Notch3v EGF-like repeat domains. Eur J Hum Genet 2000, 8:280-285

20. Joutel A, Vahedi K, Corpechot C, Troesch A, Chabriat H, Vayssière C, Cruaud C, Maciazek J, Weissenbach J, Bousser M-G: Strong clustering and stereotyped nature of Notch3 mutations in CADASIL patients. Lancet 1997, 350:1511-1515

21. Opherk C, Duering M, Peters N, Karpinska A, Rosner S, Schneider E, Bader B, Giese A, Dichgans M: CADASIL mutations enhance spontaneous multimerization of NOTCH3. Hum Mol Genet 2009, 18: $2761-2767$

22. Arboleda-Velasquez JF, Manent J, Lee JH, Tikka S, Ospina C, Vanderburg CR, Frosch MP, Rodríguez-Falcón M, Villen J, Gygi S: Hypomorphic Notch 3 alleles link Notch signaling to ischemic cerebral small-vessel disease. Proc Natl Acad Sci 2011, 108: E128-E135 
23. Muiño E, Gallego-Fabrega C, Cullell N, Carrera C, Torres N, Krupinski J, Roquer J, Montaner J, Fernández-Cadenas I: Systematic review of cysteine-sparing NOTCH3 missense mutations in patients with clinical suspicion of CADASIL. Int J Mol Sci 2017, 18:1964

24. Abou Al-Shaar H, Qadi N, Al-Hamed MH, Meyer BF, Bohlega S: Phenotypic comparison of individuals with homozygous or heterozygous mutation of NOTCH3 in a large CADASIL family. J Neurol Sci 2016, 367:239-243

25. Tuominen S, Juvonen V, Amberla K, Jolma T, Rinne JO, Tuisku S, Kurki T, Marttila R, Pöyhönen M, Savontaus M-L: Phenotype of a homozygous CADASIL patient in comparison to 9 age-matched heterozygous patients with the same R133C Notch3 mutation. Stroke 2001, 32:1767-1774

26. Vinciguerra C, Rufa A, Bianchi S, Sperduto A, De Santis M, Malandrini A, Dotti MT, Federico A: Homozygosity and severity of phenotypic presentation in a CADASIL family. Neurol Sci 2014, 35:91-93

27. Narayan S, Gorman G, Kalaria R, Ford G, Chinnery P: The minimum prevalence of CADASIL in northeast England. Neurology 2012, 78: $1025-1027$

28. Razvi S, Davidson R, Bone I, Muir K: The prevalence of cerebral autosomal dominant arteriopathy with subcortical infarcts and leucoencephalopathy (CADASIL) in the west of Scotland. J Neurol Neurosurg Psychiatr 2005, 76:739-741

29. Moreton F, Razvi S, Davidson R, Muir K: Changing clinical patterns and increasing prevalence in CADASIL. Acta Neurol Scand 2014, 130:197-203

30. Rutten JW, Boon EM, Liem MK, Dauwerse JG, Pont MJ, Vollebregt E, Maat-Kievit AJ, Ginjaar HB, Lakeman P, van Duinen SG: Hypomorphic NOTCH 3 alleles do not cause CADASIL in humans. Hum Mutat 2013, 34:1486-1489

31. Huneau C, Houot M, Joutel A, Béranger B, Giroux C, Benali H, Chabriat H: Altered dynamics of neurovascular coupling in CADASIL. Ann Clin Transl Neurol 2018, 5:788-802

32. Liem M, Oberstein SL, Haan J, Boom R, Ferrari M, Buchem M, Grond J: Cerebrovascular reactivity is a main determinant of white matter hyperintensity progression in CADASIL. Am J Neuroradiol 2009, 30:1244-1247

33. Ruchoux MM, Maurage CA: CADASIL: cerebral autosomal dominant arteriopathy with subcortical infarcts and leukoencephalopathy. J Neuropathol Exp Neurol 1997, 56:947-964

34. Baudrimont M, Dubas F, Joutel A, Tournier-Lasserve E, Bousser MG: Autosomal dominant leukoencephalopathy and subcortical ischemic stroke: a clinicopathological study. Stroke 1993, 24:122-125

35. Tikka S, Mykkanen K, Ruchoux MM, Bergholm R, Junna M, Poyhonen M, Yki-Jarvinen H, Joutel A, Viitanen M, Baumann M, Kalimo H: Congruence between NOTCH3 mutations and GOM in 131 CADASIL patients. Brain 2009, 132:933-939

36. Ishiko A, Shimizu A, Nagata E, Takahashi K, Tabira T, Suzuki N: Notch3 ectodomain is a major component of granular osmiophilic material (GOM) in CADASIL. Acta Neuropathol 2006, 112: 333-339

37. Yamamoto Y, Craggs LJ, Watanabe A, Booth T, Attems J, Low RW, Oakley AE, Kalaria RN: Brain microvascular accumulation and distribution of the NOTCH3 ectodomain and granular osmiophilic material in CADASIL. J Neuropathol Exp Neurol 2013, $72: 416-431$

38. Joutel A, Haddad I, Ratelade J, Nelson MT: Perturbations of the cerebrovascular matrisome: a convergent mechanism in small vessel disease of the brain? J Cereb Blood Flow Metab 2016, 36:143-157

39. Arboleda-Velasquez JF, Zhou Z, Shin HK, Louvi A, Kim H-H, Savitz SI, Liao JK, Salomone S, Ayata C, Moskowitz MA: Linking Notch signaling to ischemic stroke. Proc Natl Acad Sci U S A 2008, 105:4856-4861

40. Baron-Menguy C, Domenga-Denier V, Ghezali L, Faraci FM, Joutel A: Increased Notch3 activity mediates pathological changes in structure of cerebral arteries. Hypertension 2017, 69: $60-70$

41. Moccia M, Mosca L, Erro R, Cervasio M, Allocca R, Vitale C, Leonardi A, Caranci F, Del Basso-De Caro ML, Barone P: Hypomorphic NOTCH3 mutation in an Italian family with CADASIL features. Neurobiol Aging 2015, 36:547.e5-547.e11

42. Erro R, Moccia M, Cervasio M, Penco S, De Caro M, Barone P: Are granular osmiophilic material deposits an epiphenomenon in CADASIL? Folia Neuropathol 2015, 53:168-171

43. Fouillade C, Chabriat H, Riant F, Mine M, Arnoud M, Magy L, Bousser MG, Tournier-Lasserve E, Joutel A: Activating NOTCH3 mutation in a patient with small-vessel-disease of the brain. Hum Mutat 2008, 29:452

44. Joutel A: Pathogenesis of CADASIL: transgenic and knock-out mice to probe function and dysfunction of the mutated gene, Notch3, in the cerebrovasculature. Bioessays 2011, 33:73-80

45. Joutel A: The NOTCH3ECD cascade hypothesis of cerebral autosomal-dominant arteriopathy with subcortical infarcts and leukoencephalopathy disease. Neurol Clin Neurosci 2015, 3:1-6

46. Meng H, Zhang X, Yu G, Lee SJ, Chen YE, Prudovsky I, Wang MM: Biochemical characterization and cellular effects of CADASIL mutants of NOTCH3. PLoS One 2012, 7:e44964

47. Monet-Leprêtre M, Haddad I, Baron-Menguy C, Fouillot-Panchal M, Riani M, Domenga-Denier V, Dussaule C, Cognat E, Vinh J, Joutel A: Abnormal recruitment of extracellular matrix proteins by excess Notch3ECD: a new pathomechanism in CADASIL. Brain 2013, 136:1830-1845

48. Duering M, Karpinska A, Rosner S, Hopfner F, Zechmeister M, Peters N, Kremmer E, Haffner C, Giese A, Dichgans M: Co-aggregate formation of CADASIL-mutant NOTCH3: a single-particle analysis. Hum Mol Genet 2011, 20:3256-3265

49. Kast J, Hanecker P, Beaufort N, Giese A, Joutel A, Dichgans M, Opherk C, Haffner C: Sequestration of latent TGF- $\beta$ binding protein 1 into CADASIL-related Notch3-ECD deposits. Acta Neuropathol Commun 2014, 2:96

50. Zhang X, Lee SJ, Young MF, Wang MM: The small leucine-rich proteoglycan BGN accumulates in CADASIL and binds to NOTCH3. Transl Stroke Res 2015, 6:148-155

51. Takahashi K, Adachi K, Yoshizaki K, Kunimoto S, Kalaria RN, Watanabe A: Mutations in NOTCH3 cause the formation and retention of aggregates in the endoplasmic reticulum, leading to impaired cell proliferation. Hum Mol Genet 2010, 19:79-89

52. Capone C, Dabertrand F, Baron-Menguy C, Chalaris A, Ghezali L, Domenga-Denier V, Schmidt S, Huneau C, Rose-John S, Nelson MT, Joutel A: Mechanistic insights into a TIMP3-sensitive pathway constitutively engaged in the regulation of cerebral hemodynamics. Elife 2016, 5:e17536

53. Gravesteijn G, Munting LP, Overzier M, Mulder AA, Hegeman I, Derieppe M, Koster AJ, van Duinen SG, Meijer OC, Aartsma-Rus A: Progression and classification of granular osmiophilic material (GOM) deposits in functionally characterized human NOTCH3 transgenic mice. Transl Stroke Res 2020, 11:517-527

54. Mestre H, Kostrikov S, Mehta RI, Nedergaard M: Perivascular spaces, glymphatic dysfunction, and small vessel disease. Clin Sci 2017, 131:2257-2274

55. Carare R, Hawkes C, Jeffrey M, Kalaria R, Weller R: Cerebral amyloid angiopathy, prion angiopathy, CADASIL and the spectrum of protein elimination failure angiopathies (PEFA) in neurodegenerative disease with a focus on therapy. Neuropathol Appl Neurobiol 2013 , 39:593-611

56. Hanemaaijer ES, Panahi M, Swaddiwudhipong N, Tikka S, Winblad B, Viitanen M, Piras A, Behbahani H: Autophagy-lysosomal defect in human CADASIL vascular smooth muscle cells. Eur J Cell Biol 2018, 97:557-567

57. Invernizzi G, Papaleo E, Sabate R, Ventura S: Protein aggregation: mechanisms and functional consequences. Int J Biochem Cell Biol 2012, 44:1541-1554 
58. Rutten JW, Klever RR, Hegeman IM, Poole DS, Dauwerse HG, Broos LA, Breukel C, Aartsma-Rus AM, Verbeek JS, van der Weerd L: The NOTCH3 score: a pre-clinical CADASIL biomarker in a novel human genomic NOTCH3 transgenic mouse model with early progressive vascular NOTCH3 accumulation. Acta Neuropathol Commun 2015, 3:89

59. Joutel A, Favrole P, Labauge P, Chabriat H, Lescoat C, Andreux F, Domenga V, Cécillon M, Vahedi K, Ducros A: Skin biopsy immunostaining with a Notch3 monoclonal antibody for CADASIL diagnosis. Lancet 2001, 358:2049-2051

60. Dabertrand F, Krøigaard C, Bonev AD, Cognat E, Dalsgaard T, Domenga-Denier V, Hill-Eubanks DC, Brayden JE, Joutel A, Nelson MT: Potassium channelopathy-like defect underlies earlystage cerebrovascular dysfunction in a genetic model of small vessel disease. Proc Natl Acad Sci U S A 2015, 112:E796-E805

61. Capone C, Cognat E, Ghezali L, Baron-Menguy C, Aubin D, Mesnard L, Stohr H, Domenga-Denier V, Nelson MT, Joutel A: Reducing Timp3 or vitronectin ameliorates disease manifestations in CADASIL mice. Ann Neurol 2016, 79:387-403

62. Ghezali L, Capone C, Baron-Menguy C, Ratelade J, Christensen S, Østergaard Pedersen L, Domenga-Denier V, Pedersen JT, Joutel A: Notch3ECD immunotherapy improves cerebrovascular responses in CADASIL mice. Ann Neurol 2018, 84:246-259

63. Rutten JW, Dauwerse HG, Peters DJ, Goldfarb A, Venselaar H, Haffner C, van Ommen G-JB, Aartsma-Rus AM, Lesnik Oberstein SA: Therapeutic NOTCH3 cysteine correction in CADASIL using exon skipping: in vitro proof of concept. Brain 2016, 139: $1123-1135$

64. Gravesteijn G, Dauwerse JG, Overzier M, Brouwer G, Hegeman I, Mulder AA, Baas F, Kruit MC, Terwindt GM, van Duinen SG, Jost CR, Aartsma-Rus A, Lesnik Oberstein SAJ, Rutten JW: Naturally occurring NOTCH3 exon skipping attenuates NOTCH3 protein aggregation and disease severity in CADASIL patients. Hum Mol Genet 2020, 29:1853-1863

65. Lewandowska E, Leszczynska A, Wierzba-Bobrowicz T, Skowronska M, Mierzewska H, Pasennik E, Czlonkowska A: Ultrastructural picture of blood vessels in muscle and skin biopsy in CADASIL. Folia Neuropathol 2006, 44:265

66. Ruchoux MM, Domenga V, Brulin P, Maciazek J, Limol S, TournierLasserve E, Joutel A: Transgenic mice expressing mutant Notch3 develop vascular alterations characteristic of cerebral autosomal dominant arteriopathy with subcortical infarcts and leukoencephalopathy. Am J Pathol 2003, 162:329-342

67. Pippucci T, Maresca A, Magini P, Cenacchi G, Donadio V, Palombo F, Papa V, Incensi A, Gasparre G, Valentino ML: Homozygous NOTCH 3 null mutation and impaired NOTCH 3 signaling in recessive early-onset arteriopathy and cavitating leukoencephalopathy. EMBO Mol Med 2015, 7:848-858

68. Erro R, Lees AJ, Moccia M, Picillo M, Penco S, Mosca L, Vitale C, Barone P: Progressive parkinsonism, balance difficulties, and supranuclear gaze palsy. JAMA Neurol 2014, 71:104-107

69. Wang Y, Pan L, Moens CB, Appel B: Notch3 establishes brain vascular integrity by regulating pericyte number. Development 2014, $141: 307-317$

70. Belin de Chantemele E, Retailleau K, Pinaud F, Vessières E, Bocquet A, Guihot A-L, Lemaire B, Domenga V, Baufreton C, Loufrani L: Notch3 is a major regulator of vascular tone in cerebral and tail resistance arteries. Arterioscler Thromb Vasc Biol 2008, 28: 2216-2224

71. Jin S, Hansson EM, Tikka S, Lanner F, Sahlgren C, Farnebo F, Baumann M, Kalimo H, Lendahl U: Notch signaling regulates platelet-derived growth factor receptor- $\boldsymbol{\beta}$ expression in vascular smooth muscle cells. Circ Res 2008, 102:1483-1491

72. Craggs LJ, Fenwick R, Oakley AE, Ihara M, Kalaria RN: Immunolocalization of platelet-derived growth factor receptor- $\beta$ (PDGFR- $\beta$ ) and pericytes in cerebral autosomal dominant arteriopathy with subcortical infarcts and leukoencephalopathy (CADASIL). Neuropathol Appl Neurobiol 2015, 41:557-570

73. Machuca-Parra AI, Bigger-Allen AA, Sanchez AV, Boutabla A, Cardona-Velez J, Amarnani D, Saint-Geniez M, Siebel CW, Kim LA, D'Amore PA, Arboleda-Velasquez JF: Therapeutic antibody targeting of Notch3 signaling prevents mural cell loss in CADASIL. J Exp Med 2017, 214:2271-2282

74. Proweller A, Wright AC, Horng D, Cheng L, Lu MM, Lepore JJ, Pear WS, Parmacek MS: Notch signaling in vascular smooth muscle cells is required to pattern the cerebral vasculature. Proc Natl Acad Sci U S A 2007, 104:16275-16280

75. Arboleda-Velasquez JF, Lopera F, Lopez E, Frosch MP, SepulvedaFalla D, Gutierrez JE, Vargas S, Medina M, Martinez De Arrieta C, Lebo RV, Slaugenhaupt SA, Betensky RA, Villegas A, ArcosBurgos M, Rivera D, Restrepo JC, Kosik KS: C455R notch3 mutation in a Colombian CADASIL kindred with early onset of stroke. Neurology 2002, 59:277-279

76. Joutel A, Monet M, Domenga V, Riant F, Tournier-Lasserve E: Pathogenic mutations associated with cerebral autosomal dominant arteriopathy with subcortical infarcts and leukoencephalopathy differently affect Jagged1 binding and Notch3 activity via the RBP/JK signaling pathway. Am J Hum Genet 2004, 74:338-347

77. Peters N, Opherk C, Zacherle S, Capell A, Gempel P, Dichgans M: CADASIL-associated Notch3 mutations have differential effects both on ligand binding and ligand-induced Notch3 receptor signaling through RBP-Jk. Exp Cell Res 2004, 299:454-464

78. Monet-Leprêtre M, Bardot B, Lemaire B, Domenga V, Godin O, Dichgans M, Tournier-Lasserve E, Cohen-Tannoudji M, Chabriat H, Joutel A: Distinct phenotypic and functional features of CADASIL mutations in the Notch3 ligand binding domain. Brain 2009, 132: $1601-1612$

79. Braune E-B, Lendahl U: Notch — a goldilocks signaling pathway in disease and cancer therapy. Discov Med 2016, 21:189-196

80. de los Angeles Serrano M, Demarest BL, Tone-Pah-Hote T, TristaniFirouzi M, Yost HJ: Inhibition of Notch signaling rescues cardiovascular development in Kabuki syndrome. PLoS Biol 2019, 17: e3000087

81. Greisenegger EK, Llufriu S, Chamorro A, Cervera A, JimenezEscrig A, Rappersberger K, Marik W, Greisenegger S, Stögmann E, Kopp T: A NOTCH3 homozygous nonsense mutation in familial Sneddon syndrome with pediatric stroke. J Neurol 2021, 268: 810-816

82. Bentley P, Wang T, Malik O, Nicholas R, Ban M, Sawcer S, Sharma P: CADASIL with cord involvement associated with a novel and atypical NOTCH3 mutation. J Neurol Neurosurg Psychiatr 2011, $82: 855-860$

83. Dotti MT, De Stefano N, Bianchi S, Malandrini A, Battisti C, Cardaioli E, Federico A: A novel NOTCH3 frameshift deletion and mitochondrial abnormalities in a patient with CADASIL. Arch Neurol 2004, 61:942-945

84. Yoon CW, Kim Y-E, Seo SW, Ki C-S, Choi SH, Kim J-W, Na DL: NOTCH3 variants in patients with subcortical vascular cognitive impairment: a comparison with typical CADASIL patients. Neurobiol Aging 2015, 36:2443.e1-2443.e7

85. Testi S, Malerba G, Ferrarini M, Ragno M, Pradotto L, Mauro A, Fabrizi G: Mutational and haplotype map of NOTCH3 in a cohort of Italian patients with cerebral autosomal dominant arteriopathy with subcortical infarcts and leukoencephalopathy (CADASIL). J Neurol Sci 2012, 319:37-41

86. Schubert V, Bender B, Kinzel M, Peters N, Freilinger T: A novel frameshift variant in the CADASIL gene NOTCH3: pathogenic or not? J Neurol 2018, 265:1338-1342

87. Rutten JW, Van Eijsden BJ, Duering M, Jouvent E, Opherk C, Pantoni L, Federico A, Dichgans M, Markus HS, Chabriat H: The effect of NOTCH3 pathogenic variant position on CADASIL disease severity: NOTCH3 EGFr 1-6 pathogenic variant are associated with 
a more severe phenotype and lower survival compared with EGFr 7-34 pathogenic variant. Genet Med 2019, 21:676-682

88. La Piana R, Leppert IR, Pike GB, Lanthier S, Brais B, Tampieri D: 3T MRI study discloses high intrafamilial variability in CADASIL due to a novel NOTCH3 mutation. J Clin Neurosci 2018, 58:25-29

89. Schmidt H, Zeginigg M, Wiltgen M, Freudenberger P, Petrovic K, Cavalieri M, Gider P, Enzinger C, Fornage M, Debette S: Genetic variants of the NOTCH3 gene in the elderly and magnetic resonance imaging correlates of age-related cerebral small vessel disease. Brain 2011, 134:3384-3397

90. Ross OA, Soto-Ortolaza AI, Heckman MG, Verbeeck C, Serie DJ, Rayaprolu S, Rich SS, Nalls MA, Singleton A, Guerreiro R: NOTCH3 variants and risk of ischemic stroke. PLoS One 2013, 8: e75035

91. Karczewski KJ, Francioli LC, Tiao G, Cummings BB, Alföldi J, Wang Q, Collins RL, Laricchia KM, Ganna A, Birnbaum DP: The mutational constraint spectrum quantified from variation in 141,456 humans. Nature 2020, 581:434-443

92. Li K, Li Y, Wu W, Gordon WR, Chang DW, Lu M, Scoggin S, Fu T, Vien L, Histen G, Zheng J, Martin-Hollister R, Duensing T, Singh S, Blacklow SC, Yao Z, Aster JC, Zhou BB: Modulation of Notch signaling by antibodies specific for the extracellular negative regulatory region of NOTCH3. J Biol Chem 2008, 283:8046-8054

93. Primo V, Graham M, Bigger-Allen AA, Chick JM, Ospina C, Quiroz YT, Manent J, Gygi SP, Lopera F, D’Amore PA, ArboledaVelasquez JF: Blood biomarkers in a mouse model of CADASIL. Brain Res 2016, 1644:118-126
94. Ayata C: CADASIL: experimental insights from animal models. Stroke 2010, 41:S129-S134

95. Monet M, Domenga V, Lemaire B, Souilhol C, Langa F, Babinet C, Gridley T, Tournier-Lasserve E, Cohen-Tannoudji M, Joutel A: The archetypal R90C CADASIL-NOTCH3 mutation retains NOTCH3 function in vivo. Hum Mol Genet 2007, 16:982-992

96. Cognat E, Baron-Menguy C, Domenga-Denier V, Cleophax S, Fouillade C, Monet-Lepretre M, Dewerchin M, Joutel A: Archetypal Arg169Cys mutation in NOTCH3 does not drive the pathogenesis in cerebral autosomal dominant arteriopathy with subcortical infarcts and leucoencephalopathy via a loss-of-function mechanism. Stroke 2014, 45:842-849

97. Haritunians T, Chow T, De Lange R, Nichols J, Ghavimi D, Dorrani N, St Clair DM, Weinmaster G, Schanen C: Functional analysis of a recurrent missense mutation in Notch3 in CADASIL. J Neurol Neurosurg Psychiatr 2005, 76:1242-1248

98. Low W-C, Santa Y, Takahashi K, Tabira T, Kalaria RN: CADASILcausing mutations do not alter Notch3 receptor processing and activation. Neuroreport 2006, 17:945-949

99. Karlström H, Beatus P, Dannaeus K, Chapman G, Lendahl U, Lundkvist J: A CADASIL-mutated Notch 3 receptor exhibits impaired intracellular trafficking and maturation but normal ligandinduced signaling. Proc Natl Acad Sci U S A 2002, 99:17119-17124

100. Watanabe H, Shen J: Dominant negative mechanism of presenilin-1 mutations in FAD. Proc Natl Acad Sci U S A 2017, 114:12635-12637

101. Donahue CP, Kosik KS: Distribution pattern of Notch3 mutations suggests a gain-of-function mechanism for CADASIL. Genomics 2004, 83:59-65 